\title{
Allowing pseudoscience into EU risk assessment processes is eroding public trust in science experts and in science as a whole: the bigger picture
}

Daniel R. Dietrich ${ }^{1}$, Wolfgang Dekant ${ }^{2}$, Helmut Greim ${ }^{3}$, Pat Heslop-Harrison ${ }^{4}$, Sir Colin Berry ${ }^{5}$, Alan Boobis ${ }^{6}$, Jan Hengstler ${ }^{7}$ and Richard Sharpe ${ }^{8}$.

1: Human and Environmental Toxicology, University of Konstanz, 78457 Konstanz, Germany; +49 (0)7531 883518; Daniel.Dietrich@uni-konstanz.de

2: Department of Toxicology, University of Wuerzburg, Versbacher Str. 9, 97078 Wuerzburg, Germany; +49 (0)931 3148449; dekant@toxi.uni-wuerzburg.de

3: Technical University of Munich, Hohenbachernstr. 15-17, 85354 Freising-Weihenstephan, Germany, ; +49 (0)8161 715600, helmut.greim@Irz.tu-muenchen.de

4: Department of Genetics, University Road, University of Leicester, LE1 7RH

United Kingdom; +44 (0)116 252 5079, phh4@leicester.ac.uk

${ }^{5}$ : Queen Mary - Pathology, Queen Mary, London, London E1 4NS, United Kingdom; colin@sircolinberry.co.uk

${ }^{6}$ : Department of Medicine, Hammersmith Campus, Imperial College London, London W12 ONN, United Kingdom; +44 (0)20 7594 6805, a.boobis@imperial.ac.uk

7: Department of Toxicology, IfADo, Ardeystrasse 67, 44139 Dortmund, Germany; +49 (0)231 1084 348; hengstler@ifado.de

8: MRC Centre for Reproductive Health, 47 Little France Crescent, University of Edinburgh, Edinburgh EH16 4TJ United Kingdom; +44 (0)131-242-6387, r.sharpe@ed.ac.uk

Chemico-Biological Interactions, 2016, doi: 10.1016/j.cbi.2016.07.023, in press

Imagine we are beamed back into the $12^{\text {th }}$ century and are staying overnight at a country tavern. We by our clothes met with both curiosity and hostility from the tavern regulars. In the middle of the night we are roughly wakened by the owner and some of his men and directly accused of having stolen from one of the regulars after first poisoning him. Despite our protests and the lack of any reasonable proof we are accused of being thieves and murderers and are subjected to trial by ordeal to prove our innocence.

The trial takes the form of having our hands and feet tied and being thrown into the river; if we sink and drown we are obviously guilty, however if we float God has recognized our innocence and lets us live (judicium Dei). To a scientist, it seems likely we would drown.

Thankfully, over the past 800 years the development of the judicial system has brought us to the point where an accused is considered innocent until proven guilty. Whether the context is Criminal, where a "beyond reasonable doubt" standard of proof is required, or Civil, where the "balance of probability" is the standard, the burden of proof lies with the accusing party, but in either case is based on objective evidence.

If we were in the tavern now, it would be necessary for the accuser (or his legal representative) to prove, beyond reasonable doubt in this case, that we had poisoned the man and stolen the goods from him. In practice, the onus of the demonstration of proof on the accuser is not restricted to criminal cases but applies to many legal procedures in democracies.

Unfortunately Europe, in the application of its legislation relating to chemicals, is in danger of falling back into the medieval approach. The most recent example is the advocacy 
group- [1], media- and NGO- [2] driven move to have glyphosate banned, despite solid evidence and multiple expert assessments [3-5] that this herbicide is without risk to consumers and is the herbicide with the least negative environmental and health impact. The "public" is being misled by pseudoscientists to believe that the compound is highly dangerous to humans and the environment, a claim that runs counter to the evidence and to expert (critical) assessment of that evidence. The media are rife with quotes from poorly informed and often scientifically less well-informed politicians and others who had analysed their water, urine, beer, and vegetables and reported trace amounts of glyphosate, fourthousand-fold below potentially harmful levels for humans [6]. Under this onslaught of misinformation, decision-makers may prefer to disregard evidence-based data that contradict a precautionary viewpoint.

In a similarly misleading vein, there have been seemingly endless discussions about "endocrine disrupters" and their postulated human health effects, based on association studies. For these to be causal, they require us to accept that extremely low-level exposures cause effects in humans, whereas most of the experimental data indicate such exposures are without effect. Most recently, the debate on "endocrine disruptors" has shifted focus to the concept that doses of these compounds below their 'no-observed-effect level' (in animal and in vitro studies) can cause adverse effects (so-called non-monotonic doseresponse curves) [7], even though the evidence that endocrine systems can be perturbed in this way just does not exist; indeed, there is ample human data on abnormally low hormone exposures that tell us this is not how such systems work. However, this detailed evidence is being ignored and the most prominent proponents of endocrine disruption-mediated human health effects are now using this to argue that hazard identification alone is necessary for regulatory purposes [7]. However, hazard characterization, including potency evaluation, and exposure assessment are the principles on which the protection of humans from adverse effects of environmental chemicals is undertaken, and has proved to be very effective. This is also the consensus approach recommended for endocrine disrupters [8]. This is a logical path that demands detailed evidence gathering and weighing of the science that then forms the basis of the information on which the legal process is based. Do we want to throw this trusted and tried process away?

Relying on hazard identification alone relieves the "accusing party" of the burden of proof (i.e. obtaining the evidence) and allows for endless new allegations of potential effects on human health, for which evidence is not required - it is simply assumed to be present. We don't think that any of us would like our doctors to use similar approaches for looking after our health; no, doctors want evidence of what is wrong so that they can target it specifically to restore normal health. The consequences of doing otherwise can be fatal [9]. What about the wider implications of a hazard-based approach? Will we ban cars or aeroplanes because they are clearly hazardous, or oxygen and water because they are hazardous to human health? In this regard, the putative hazard has now changed; now endocrine disrupters are being advocated as a prime cause for obesity and type II diabetes [10]. How credible is this? We know that obesity and type II diabetes can often be corrected by reducing appetite, food intake and additional exercise, difficult though this may be, but what evidence is there that reducing exposure to so-called endocrine-disrupting 'obesogens' can reduce the incidence of obesity and type II diabetes? There is no such evidence, yet we are asked to believe that 'obesogens' are an important human health risk and because of this should be the major focus of future research and regulation efforts in this area [11]. Like medieval justice, the accusing (scaremongering) party never faces the consequences of their 
accusations or allegations. On the contrary, the accusing party will benefit from the uncertainty introduced. However, any damages incurred, whether these be to human health, through unintended consequences, society or the economy [12], are common good and not the responsibility of the accusing party.

These trends are testimony to the apparent movement to overturn the use of verifiable facts and evidence-based risk assessment in regulation and politics. Further, they undermine the concept of burden of proof, central to our judicial systems, developed over the past centuries. Indeed, arguably, undue emphasis on hazard identification alone has already found its way into some EU chemicals legislation, ignoring more informative weight of evidence and risk assessment approaches, based on sound science, that have served society well over the years. Indeed, it is not merely chemical risk assessment that is currently at stake, it is science as a whole. Reports of the lack of reproducibility of published scientific findings [13] and public disagreement among scientists (and pseudoscientists) on the dangers of compounds, despite good evidence to the contrary, erodes public trust in scientists, and science as a whole - few without scientific training realize that science progresses by the detection of, and subsequent elimination of, errors. This is why acting on findings in isolation, all too common an occurrence today, is an unsound strategy. Perhaps equally important, failure of decision makers to recognise this, leads to unnecessarily restrictive and potentially damaging regulation.

Arguments such as those we voice above are now routinely attacked, sometimes with blatant disregard for the facts and scientific evidence provided, on the basis that 'this is what the chemical industry wants, so these authors must be speaking on behalf of that industry' or worse 'these scientist must be paid by industry, thus are corrupt and therefore trivialize hazards' [14-16]. This is not the case! But such unwarranted accusations of conflicts of interest in the absence of robust scientific evidence to support their assertions $[17,18]$, have become the mode du jour in such disputes [19]. In some cases, this has resulted in conflict of interest policies that could lead to an overall lack of scientific balance among the group of experts considered not to be thus conflicted. A number of NGO's have an interest in maintaining public concerns about specific issues, and indeed may rely on such concerns for charitable donations. Hence, there is a strong motivation to disregard data that contradicts a precautionary point of view. Regrettably, some scientists appear to put the need to obtain research funding above the objective appraisal of the evidence. Unlike potential financial bias, these possible conflicts of interest [19] are rarely considered in such debates. But these attitudes can distort opinions provided to organisations such as EFSA, WHO, WHO/IARC, EPA and others. The consequence is that scientific argument and weight of evidence that might disagree with the initial allegation or accusation, can be undermined. This process damages the credibility of governmental organizations and the well-developed processes that are the very foundations of our society and our well-being. Simply following the discussion on the alleged effects of MMR vaccine on autism provides ample evidence of this [20].

For sure, the chemical industry has every interest in protecting its products and profits, and will lobby to this effect. However, to ensure longevity of their products and to avoid litigation, industry is as interested in an evidence-based approach to risk assessment as we are, and collecting the evidence is a huge and expensive task that industry has to undertake, as is mandated by the regulating authorities, to justify the safety of its products. Is it sensible to say "No" to such evidence and instead to assume that if a chemical is hazardous it should be banned, irrespective of how low the concentrations are that we, the public, are 
exposed to? In essence, we would be saying that an evidence-based approach is not as good as a presumptive approach based on no evidence. This is to throw away scientific principles and good practice and to replace it with something akin to witchcraft.

It is time to end the influence of pseudoscience and pseudoscientists, including some self-appointed public advocacy groups, on European legislation. We advocate this not because of what the chemical industry may want or not want, but because it is the most credible, scientifically-sound and societally-beneficial solution, utilising well-defined and transparent processes of evidence gathering, weighing and risk assessment that should be at the core of decisions that support all legal procedures. This system is what has been developed, tried and tested in Europe over the years and is demonstrably protective of human health. Thus this surely should have been the aim of the European Commission in its decision on the criteria for EDCs in the regulation of biocides and pesticides [21].

\section{References}

[1] A.T.W.I. Action, Protect our health, Stop Monsanto, 2016.

[2] P.A.N. Europe, Environmental NGOs press charges against monsanto, German government institute and European Food Safety Authority, 2016.

[3] J. FAO/WHO, Pesticide residues in food 2016. Special Session of the Joint FAO/WHO Meeting on Pesticide Residues, in: J. FAO/WHO (Ed.), JMPR FAO/WHO, 2016, pp. 123.

[4] B.f. Risikobewertung, The $B f R$ has finalised its draft report for the re-evaluation of glyphosate, BfR, Berlin, 2015.

[5] E.F.S. Authority, Conclusion on the peer review of the pesticide risk assessment of the active substance glyphosate EFSA Journal, 13 (2015) 4302-4408.

[6] B.f. Risikobewertung, Glyphosate in Urine - Concentrations are far below the range indicating a potential health hazard Opinion No. 014/2013Berlin, 2013.

[7] E. News, Society Leaders Help Inform International EDC Regulations, 2016.

[8] R. Solecki, A. Kortenkamp, Å. Bergman, I. Chahoud, G.H. Degen, D.R. Dietrich, H. Greim, H. Håkansson, U. Hass, T. Husoy, M. Jacobs, S. Jobling, A. Mantovani, P. Marx-Stoelting, A. Piersma, R. Slama, R. Stahlmann, M. van den Berg, R.T. Zoeller, A.R. and Boobis, "Scientific principles for the identification of endocrine disrupting chemicals - a consensus statement" Environmental health perspectives, in press (2016).

[9] P. Posadzki, A. Alotaibi, E. Ernst, Adverse effects of homeopathy: a systematic review of published case reports and case series., Int J Clin Pract., 66 (2012) 1178-1188.

[10] J. Legler, T. Fletcher, E. Govarts, M. Porta, B. Blumberg, J.J. Heindel, L. Trasande, Obesity, diabetes, and associated costs of exposure to endocrine-disrupting chemicals in the European union, The Journal of clinical endocrinology and metabolism, 100 (2015) 1278-1288.

[11] J.J.e.a. Heindel, Parma consensus statement on metabolic disruptors, Environmental Health, (2015) 14-54.

[12] D.R. Dietrich, w. Dekant, H. Greim, P. Heslop-Harrison, C. Berry, A. Boobis, J. Hengstler, R.M. Sharpe, Don't mar legilsation with pseudoscience., Nature, 535 (2016) 355.

[13] M. Baker, 1,500 scientists lift the lid on reproducibility, Nature, 533 (2016) 452-454.

[14] J. Garwood, Do toxic editors trivialise hidden hazards?, Lab Times, 3 (2014) 39-42.

[15] S. Horel, A Toxic Affair: Season Finale, Corporate Europe Observatory, 2016.

[16] S. Horel, B. Bienkowsi, Special report: Scientists critical of EU chemical policy have industry ties, Environmental Health News, 2013. 
[17] R. Slama, J.P. Bourguignon, B. Demeneix, R. Ivell, G. Panzica, A. Kortenkamp, T. Zoeller, Scientific Issues Relevant to Setting Regulatory Criteria to Identify Endocrine Disrupting Substances in the European Union, Environmental health perspectives, (2016).

[18] P. Grandjean, D. Ozonoff, Transparency and translation of science in a modern world, Environmental Health, 12 (2013) 70.

[19] D.R. Dietrich, J.G. Hengstler, Conflict of interest statements: current dilemma and a possible way forward, Arch Toxicol, (2016), doi: 10.1007/s00204-016-1783-y.

[20] P. Hobson-West, 'Trusting blindly can be the biggest risk of all': organised resistance to childhood vaccination in the UK, Sociol Health Illn, 29 (2007) 198-215.

[21] E. Commission, Press Release 15.06.2016: Commission presents scientific criteria to identify endocrine disruptors in the pesticides and biocides areas, European Commission, Bruxelles, 2016. 